Discussion Paper No. 15-071

The Perils of Debt Deflation in the Euro Area -

A Multi Regime Model

Willi Semmler and Alexander Haider

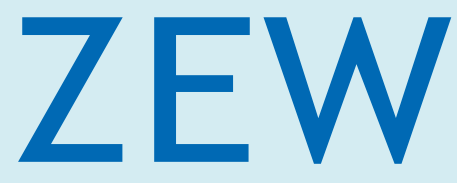

Zentrum für Europäische Wirtschaftsforschung $\mathrm{GmbH}$

Centre for European

Economic Research 


\section{Discussion Paper No. 15-071 \\ The Perils of Debt Deflation in the Euro Area - A Multi Regime Model}

Willi Semmler and Alexander Haider

Download this ZEW Discussion Paper from our ftp server:

http://ftp.zew.de/pub/zew-docs/dp/dp15071.pdf

Die Discussion Papers dienen einer möglichst schnellen Verbreitung von neueren Forschungsarbeiten des ZEW. Die Beiträge liegen in alleiniger Verantwortung der Autoren und stellen nicht notwendigerweise die Meinung des ZEW dar.

Discussion Papers are intended to make results of ZEW research promptly available to other economists in order to encourage discussion and suggestions for revisions. The authors are solely responsible for the contents which do not necessarily represent the opinion of the ZEW. 


\title{
The Perils of Debt Deflation in the Euro Area - A Multi Regime Model
}

\author{
Willi Semmler* \\ Alexander Haider ${ }^{\dagger}$
}

August 12, 2015

\begin{abstract}
Academic research and policy makers in the Euro area are currently concerned with the threat of debt deflation and secular stagnation in Europe. Empirical evidence seems to suggest that secular stagnation and debt deflation in the Euro area may be rather slowly developing. Yet what appears as major peril is that debt deflation with a lack of economic growth, rising real interest rates and further rising debt may trigger household defaults, defaults of firms and banks, rise of risk premia, and default risk of certain sectors of the economy or sovereign defaults. It is this rising default and financial risk then that may lead to a regime change to a slowly moving debt crisis with high financial risk and high financial stress. In order to explore those issues, a macro policy model of Svensson type is introduced, exhibiting a regime of low and high financial stress. Then, a four dimensional multi-regime VAR is employed to an Euro area data set to support the theoretical model and the claim that in particular Southern Euro area countries are affected by debt deflation and financial market stress.
\end{abstract}

Keywords: Debt Deflation, Secular Stagnation, Euro Area, Interest Rate Spread, Multi Regime Model

JEL-Classification: E430, F36, F450

\footnotetext{
*Henry Arnhold Professor of Economics, Department of Economics, The New School for Social Research, 79 Fifth Ave., New York, NY 10003, United States and Research Associate, ZEW, Mannheim, Germany, Tel.:(212)-2295717 x 3050, Fax: (212)-229-5724, E-mail: semmlerw@ newschool.edu

${ }^{\dagger}$ Department of Economics, The New School for Social Research, 79 Fifth Ave., New York, NY 10003, United States, E-mail: haida588@newschool.edu
} 


\section{Introduction}

Seven years after the outbreak of the financial crisis recovery is still sluggish around the world. This is especially true for the Euro area where slow recovery, solvency crisis in peripheral countries and deflationary pressure intensified the crisis. While inflation rates are already low at $0.3 \%$ for the Euro area, Italy's inflation rate is even lower at $0.2 \% .{ }^{1}$ Even more worrisome are developments in Spain and Greece where the HICP has already been negative for May 2015.

Deflation may entail several problems for the Euro area. First, as Tobin (1975) already argues, if the expected inflation rate is lower next period consumers may delay consumption demand. Secondly, the real interest rate may rise, triggering strong adverse macro feedback effects. Third, there is the risk of contagion effects. If one country suffers from a shortfall in aggregate demand, other countries may be drawn into a downward trend. Sluggish recovery of other regions may follow and lead to some wide spread "secular stagnation".

Although there is no precise definition of the term, Teulings and Baldwin (2014) argue that the profession agrees on certain characteristics, which appear to emerge now in particular in Europe. In fact, even though "secular stagnation" was first discussed in the USA, ${ }^{2}$ Europe seems to face a higher risk of falling victim to it than the USA. Although interest rates are low in Europe, some countries are already experiencing negative inflation rates, while low investment demand may require negative real interest rates to equalize saving and investment at a higher employment level.

Besides the negative effects of deflation on aggregate demand, one also has to be aware of debt deflation (Fisher 1933): even though the nominal interest may be low, a negative inflation rate will still increase the real interest rate, as well as real debt. This will lead to a rising burden of debt and further liabilities when debt is already high. Firms will then hold back investment and households postpone purchases of durable consumer goods. What one might see as a great peril is that - due to rising real debt - new insolvencies may arise in the Euro area, insolvencies of firms, in the housing sector, and in the banking sector. Though the rise of real debt and the process of secular stagnation appears to be slow currently, once insolvencies re-emerge, a financial crisis and financial stress maybe powerful forces to produce further downward movements.

While Fisher's focus is on private households or firms when analyzing debt deflation, we are analyzing the effects of deflationary shocks on the term structure/yield curve. A debt deflation may trigger financial stress, in particular as Williams and Taylor (2009) argue, through a sudden rise in interbank borrowing rates and a rise in credit spreads. This may then give, as soon as sovereign debt is involved, rise to an increase in sovereign bond spreads, which appears as the long run peril, since many long term borrowing contracts, such as mortgages are linked to long term interest rates. So what one might want to analyze more properly is the effects of a decrease in the price level on the term structure of interest rates when financial stress is involved. As a measure of the interest rate spread we can take, for example, the spread between nominal longterm (10 years) and short-term ( 3 months) interest rates. We bring in here the term structure, since this is of particular interest for private sector contracts, specially for mortgages and other credit cost, which are linked to long-term interest rates.

\footnotetext{
${ }^{1} \mathrm{HICP}$ for May 2015; https://www.ecb.europa.eu/stats/prices/hicp/html/inflation.en.html

${ }^{2}$ See Summers (2014) and Gordon (2000).
} 
Note that typically only short term interest rates, the federal funds rate/marginal lending rate, are employed in economic modeling of output and price dynamics, while long-term interest rates are neglected. But as Williams and Taylor (2009: 59) state, with respect to the US 2008-9 meltdown:

...this is a simplification because in reality the transmission mechanism involves interest rates on longer term or higher risk loans. For example, it is the Libor rate, not the overnight federal funds rate, that is linked to the interest rates on trillions of dollars in loans and securities, thus influencing spending decisions. As long as the spreads between interest rates are small or constant, as they have been in the interbank market for many years, ignoring movements in the spreads is a reasonable simplifying assumption. But the spreads have been anything but small or constant in the recent crisis.

As the aforementioned authors, and others, argue, the term structure of the interest rate is a major driving force of persistent credit spreads and high long term interest rates for the private sector. ${ }^{3}$ What we will focus on in our theory of debt deflation is the effect of the term structure of interest rates on economic activity, ${ }^{4}$ which seems to be particularly important for the sovereign debt driven Euro area countries. The above cited recent literature makes a clear case for the interaction between macroeconomic factors and the term structure. We thus think this should become a center piece of a study of debt deflation mechanisms, in particular as much as Europe is concerned.

In fact, in times of a severe economic and financial crisis, accompanied by negative inflation rates, government expenditures are very likely to exceed government revenue due to the working of automatic stabilizers and/or stimulus packages. If nominal interest rates on long-term bonds are to rise substantially due to uncertainty about future developments of the fiscal finances and the economy, then effects on real rates will be even more pronounced. This will limit the capability of fiscal authorities to stimulate the economy, or create even a slowly moving sovereign debt crisis (Semmler and Proaño 2015). For some countries in the Euro area, where recovery is weak and deflationary shocks cannot be ruled out in the near future, this may imply serious consequences. As already indicated above, this may also entail severe consequences for private sector behavior.

However, the effects of deflation on the economy are not unambiguous. Bordo and Filardo (2005) analyze the topic of deflation from a historical perspective and come to the conclusion that deflations are not always linked to an economic downturn. Instead the consequences of

\footnotetext{
${ }^{3}$ The high correlation of the private sector credit spread/bond rates with the sovereign bond rates is also stated in Corsetti et al. (2012) and Blanchard and Leigh (2013). Evidence on the important role of the jumping term spread is given in section 2 .

${ }^{4}$ The diverse relationship between the yield curve and macroeconomic variables is summarized in Gürkaynak and Wright (2012): the term structure may be used to interfere market expectations about future interest rates and inflation. The yield curve also gained additional interest after the outbreak of the financial crisis: as standard monetary policies are exhausted due to the zero lower bound, attempts to alter long-term interest rates started to feature more prominently in policy debates. Similarly McCallum (1994) discusses the significance of the yield curve for aggregate demand via changes in the risk premium, where a fall in the risk premium lowers long-term rates and increases aggregate demand.
} 
deflation depend on the state of the economy. Borio et al. (2015) also stress that a mere deflation of prices of goods and services is not necessarily linked to stagnation. Even more, the weak link between deflation and an economic downturn, which they observe in their data, can be mainly attributed to the Great Depression. At the same time, they find strong evidence for severe crisis due to asset price deflations. Similar points are also made by the ECB (2014): short-lived deflation is not an uncommon phenomenon in advanced economies after WWII and most of the time they are not harmful.

However, the experiences of Japan and Hong-Kong in the 1990s and 2000s have shown that asset-price busts after debt-financed booms lead to balance-sheet adjustments of private and public sectors with the potential to trigger a harmful and persistent period of deflation. This process is also summarized by Koo (2014): as a debt-financed boom comes to an end, and asset prices fall, the attempt to deleverage leads to "unborrowed" savings resulting in a deflationary gap. ${ }^{5}$ In such a situation monetary policy becomes ineffective, as private entities are unwilling to borrow even at very low interest rates and the public sector might have to step up and do the necessary borrowing and investment.

Of course yields on sovereign debt become an important issue then: if fiscal authorities are incapable of responding to the crisis due to rising long-term rates, positive feedback effects might lead to a further decline in income levels and an intensification of deflationary pressure. Because of this decisive role of credit expansion and rising debt during booms, we are taking it explicitly into account. Section 3.2 presents a theoretical model with financial market stress, while section 4 takes the banking sector stress variables - as part of the general stress index - into account, as we are estimating a multi-regime VAR with financial stress as the threshold variable. Our threshold variable is the ZEW Financial Condition Indices (FCI) and is taken from Schleer and Semmler (2013). ${ }^{6}$

The remainder of the paper is organized as follows. Section 2 discusses relevant literature on the topic and provides some stylized fact. Section 3 presents a theoretical model to explain how a debt deflation with high credit spread can be turned into a contractionary regime with high insolvency risk of households, firms and the sovereign, creating a high financial stress regime with adverse macro feedback effects. Section 4.1 outlines the multi regime econometric methods used and section 4.2 discusses the empirical results of our regime change analysis. Our results are summarized in section 5 .

\section{Further Literature and Stylized Facts}

As already mentioned in the introduction, Fisher (1933) presents his idea of debt-deflation as an explanation of the Great Depression. In a state of (nominal) over-indebtedness, the attempt to deleverage and increase one's net-worth leads to a contraction of the money supply and velocity. As a consequence prices fall which depresses net-worth even further. Moreover, with falling profits, reductions in output and employment follow and bankruptcies and pessimism may lead to an additional slow down in the velocity and supply of money. In the end the deflationary process leads to increasing real debt levels and disturbances in interest rates, where nominal

\footnotetext{
${ }^{5}$ A similar argument is made by Minsky (2013) (see section 2).

${ }^{6}$ See appendix B for a discussion of the data used in this study.
} 
interest may fall, but real interest rates rise. As von Peter (2005) notices, Fisher's approach was novel as he extended the known linkage between deflation and increasing real debt and discusses repercussions of financial stress on deflation. Thereby he introduces second round effects of debt deflation which makes the process inherently unstable.

Fisher's idea of debt deflation didn't catch on in mainstream macroeconomics for a long time. As Bernanke (1995) remarks, debt-deflation was only seen as a redistribution from debtors to creditors and severe macroeconomic effects were disregarded, although exceptions can be found. Tobin (1975), for example, argues that the redistribution would affect aggregate demand if marginal propensities to spend from wealth differ between creditors and debtors. In case of a higher propensity to spend from wealth for debtors, aggregate demand would decrease and aggravate an economic downturn. Additional deflationary pressure would be the result. Minsky (2013) incorporates asset markets in his theory of debt deflation where distress selling of assets to pay off debt reduces asset prices even further. This process may trigger another round of fire sales and price deflation in asset markets. Minsky also recognizes that this vicious circle might be reinforced as debtors default on their obligations, leading to capital losses for creditors and an additional weakening of aggregate demand. Similar arguments can also be found in Kindleberger and Aliber (2011).

Bernanke (1983) also takes up the topic of debt deflation and analyzes its effects on the banking system. He argues that a mere redistribution might be the case in normal circumstances, but a large deflationary shock will result in bankruptcies of debtors and a deterioration in assets of lenders. Reallocation of assets towards safer securities - and the lack of credits to riskier debtors - will then result in a credit contraction. This will lead to a persistent downturn and a decline in aggregate demand which intensifies the deflationary pressure. However, as von Peter (2005) argues, the process of debt-deflation in Bernanke (1983), as well as in Tobin (1975), is only a propagation mechanism which inhibits the system from returning to its equilibrium frictionless. Similar effects can also be found in standard macroeconomic models (e.g. Bernanke and Gertler 1989) which use to incorporate financial market conditions via the financial accelerator model, where falling net-worth of borrowers during an economic downturn increases agency costs of financing real capital investments, thereby deepening the downturn. Extensions of the financial accelerator models (e.g. Kiyotaki and Moore 1997; Bernanke et al. 1999) show how small shocks hitting the economy are magnified by financial markets imperfections. However, the financial accelerator only perturbs the adjustment process towards the steady state and shocks are of a temporary nature in these models. Similarly Christiano et al. (2004), in an attempt to model the Great Depression, build a DSGE model with assets, which can be used as collateral, debt, defaults and debt-deflation and deviations from the steady state due to a fall in investment and consumption. Still, propagation mechanism are linearized and large shocks are necessary to model the Great Depression, while stability considerations are not dealt with.

In contrast Sannikov and Brunnermeier (2010) develop a model where dropping asset prices depress investment demand which leads to a further decline in asset prices. These feedback effects keep the economy out of equilibrium and an adjustment towards the steady state is not necessarily given. They come to the conclusion that the behavior of the economy differs substantially between periods where financial markets are operating normally and periods of financial stress. Empirical evidence can be found in similar studies (e.g. Mittnik and Semmler 2013; 
Semmler and Chen 2014), where it is shown that the state of financial markets plays a crucial role with respect to the propagation of shocks. Similarly Schleer et al. (2014) develop an index of optimal leverage for 40 banks in Europe and show that credit and output contractions due to a lending shock are more severe during a period of overleveraging than during "normal times".

While the studies of debt deflation discussed so far focus on the effects of debt-deflation on the deepening of an economic downturn in terms of output, von Peter (2005) focuses on asset holding adjustments. In his overlapping generations model firms are active for three periods where revenues are only collected in the last period, such that firms have to borrow to buy assets in the first period. After a redistributive shock - which leads to debt-deflation - firms start selling their assets to reduce their indebtedness in the final period. However, distress-selling changes prices and causes second round effects of asset sales. Still, the dynamics of the model remain stable as firms without any debt are willing to increase their borrowing. On the other hand, Fisher (1933) and Minsky (2013) argue in favor of a destabilizing process which results from excess indebtedness. Debt deflation doesn't only act as a propagation mechanism, but becomes an endogenous characteristic of the economy.

While the studies discussed so far primarily focus on private indebtedness, we focus on the cost of public sector debt represented by the term structure. The dynamics of bond yields and macroeconomics variables have been studied before. Ang and Piazzesi (2003) estimate a VAR with real growth, inflation, the term structure and latent variables where identifying restrictions are informed by no arbitrage conditions. They come to the conclusion that macroeconomic factors explain movements of bond yields well, where effects of an inflation shock are the strongest in the short end of the yield curve. Evans and Marshall (2007) confirm the results of Ang and Piazzesi (2003). However, while latter stress the linkage for short- and medium-term yields, Evans and Marshall (2007) also find a significant relationship for long-term bonds. They come to the conclusion that macroeconomic factors account for most of the movement of yields up to 5 years.

Since we are particularly focusing on the Euro area and the feedback of long term interest rates and debt deflation, we want to highlight some facts of how the credit spread between short and long rates evolved after the meltdown 2008. Let us remind the reader, however, that the rise of credit spreads as Williams and Taylor (2009) describe in their study for the US, occurred exactly the same way in the Euro area. But the financial meltdown of 2008 has shown that the sovereign countries within the Euro area were evaluated differently by investors during that economic downturn, which is reflected by strong yield differentials between countries. ${ }^{7}$

While Germany, for example, is regarded as a save investment, many peripheral countries suffered from drastic increases in risk premia after the financial meltdown. Thus we are taking account of country heterogeneity within the Euro area and distinguish between core countries which are represented by Germany and France - and peripheral countries - exemplified by Italy and Spain. The development of the term spread ${ }^{8}$ since 2009 for all four countries of our study are also depicted in figure 1. As can be seen, especially Spain suffered more from increasing

${ }^{7}$ Different country risk perceptions by investors within the Euro area were of course already recognized before the recent financial crisis. For example, Codogno et al. (2003) show that bond yields in Spain and Italy rise relative to German bond yields due to an increase in international risk factors.

${ }^{8}$ For the rise of the private credit spread, we can cite again Corsetti et al. (2012) and Blanchard and Leigh (2013). 
long interest rates, compared to Germany and France.

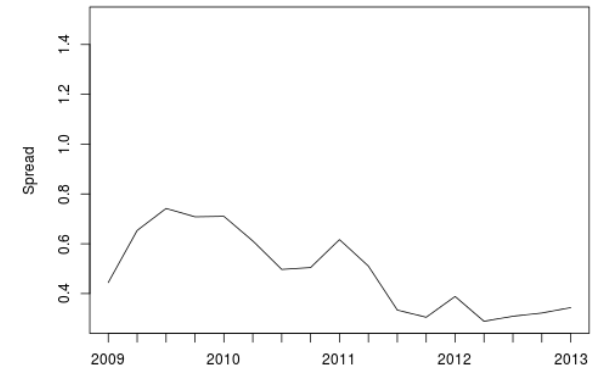

(a) Germany

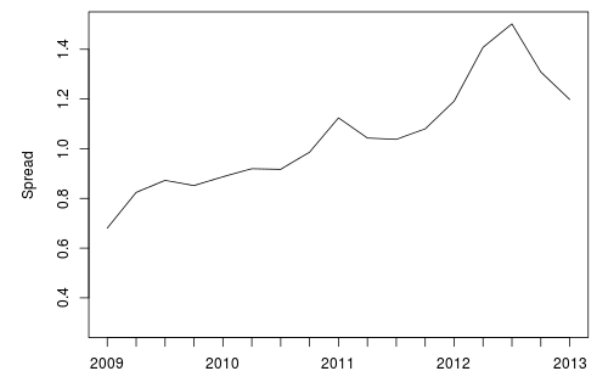

(c) Spain

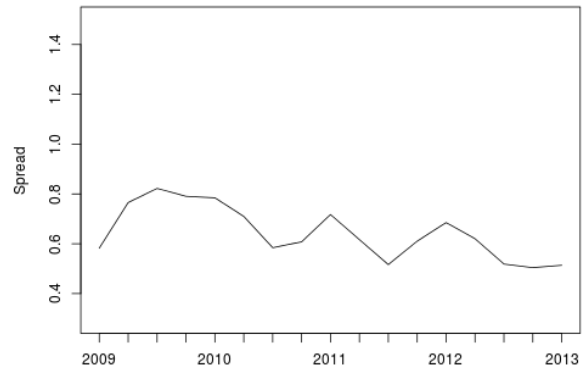

(b) France

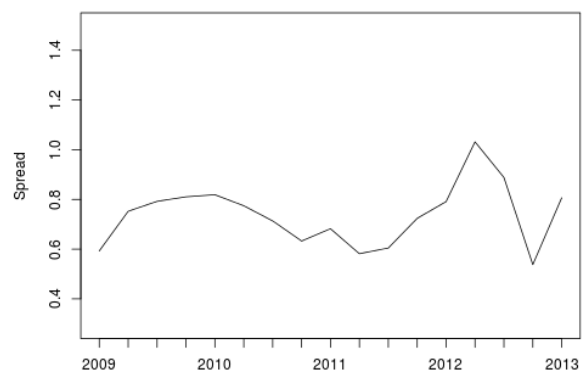

(d) Italy

Figure 1: Spread of long-term over short-term interest rate since first quarter of 2009

The database is discussed in appendix B. Though overall, as we can observe in figure 1, the spread for all countries go up after the meltdown of 2008, for the Northern countries such as France and Germany spreads soon decline, whereas for the South, for Spain and Italy spreads reach a second peak after 2012 which continue to be a peril since then. As we will demonstrate later, the regime dependent impulse responses will show a similar pattern.

\section{A monetary policy macro model}

Above we have argued that the secular stagnation effect from debt deflation in the Euro area may be rather slowly developing but the major threat is that a debt deflation, accompanied by a lack of economic growth, rising real interest rates and further rising debt, may trigger household defaults, defaults of firms, default risk of certain sectors of the economy or sovereign defaults. It is this rising default and financial crisis risk then that may lead to a regime of a slowly moving 
debt crisis with threat of banking insolvency, high financial market stress and a rapid rise of risk premia, credit spreads and persistently high term spread.

In order to give some foundation of what actually may appear as a threat, and in order to give our empirical study some foundation in a monetary policy macro model with an IS equation, a nonlinear Phillips curve, a Taylor rule, as monetary policy rule, we explore a model variant without and one with a financial stress regime. The second model variant reflects a regime switching, ${ }^{9}$ moving from little to high financial stress. The first model variant may reflect the fact that the central bank is able to reduce, or suppress, financial market stress and reduce credit spreads through QE, but in the second variant not: rather a slow moving debt crisis may evolve. In both model variants we use a Taylor monetary policy rule and track the output gap and inflation rates.

We employ here the widely used Svensson (1997) model, which, however, is formulated there in discrete time, exhibiting linear response coefficients. We extend this model by building in regime changes in the financial market. Yet, we use here a continuous time version as formulated in Werning (2011) and will discretize the model when solving it with a new numerical procedure, with NMPC, that allows for a finite decision horizon, see Grüne et al. (2013). In contrast to previous models that work with infinite time horizon we present a model variant based on a finite decision horizon.

We pursue a more realistic strategy and build a model based on a short-term behavior of agents that allows for regime changes. The infinite horizon framework implies a pronounced smoothness in the evolution of the choice variables by construction, as discussed by Grüne et al. (2013). As usual we have a central bank objective function and linear state equations in the first version. Then we introduce regime changes affecting the state equations which leads to our second version.

\subsection{Model variant without financial market stress}

Using the Svensson (1997) macro model with linear response coefficients of the state equations, we define the feedbacks of the output gap and inflation rate to both the inflation rate in the Phillips curve and to output in the IS equation. The dynamics will be presented first by using the basic Svensson (1997) model. Since there are two state equations there may already be cyclical - and not only unidirectional - change of inflation and output.

Accordingly, eqs. (6.2)-(6.5) in Svensson (1997) can be written in continuous time for shorter time horizon as ${ }^{10}$

$$
V(\pi, y)=\min _{i_{t,}} \int_{0}^{T} e^{-\rho t} \frac{1}{2}\left(\left(\pi_{t}-\pi^{*}\right)^{2}+\lambda y_{t}^{2}\right) d t
$$

subject to

$$
\dot{\pi}_{t}=\alpha_{1} \pi+\alpha_{2} y_{t}
$$

\footnotetext{
${ }^{9}$ Note that in DSGE models regime switches are also perceived as something likely to occur which some literature starts to explore now, see Farmer et al. (2009).

${ }^{10}$ For details of how such type of short decision horizon model can approximate models with longer time horizons well on the basis of much less information for the agents see Grüne et al. (2013).
} 


$$
\dot{y}=\beta_{1} y_{t}-\beta_{2}\left(i_{t}-\pi_{t}-r\right)
$$

In equ. (1) there is a quadratic penalty function which has to be minimized by choosing an interest rate $i_{t}$, as the central bank's decision variable, which may be bounded by zero. Whereas $\pi_{t}$ is the actual inflation rate, the term $\pi^{*}$ represents the target inflation rate for the central bank. There is a weight $\lambda$ attached to the output gap. The parameter $\rho$ defines the discount rate.

Note that equ. (2) represents the Phillips curve as a differential equation that defines the response of the change of the inflation rate to the inflation rate and output gap. As in Svensson (1997), those reaction coefficients, $\alpha_{1} \leq 0, \alpha_{2}>0$ are assumed to be constant. Equ. (3) is the continuous time form of the IS equation representing the output gap, $y_{t}$ given the log of actual output, $y$ minus potential output, $y^{*}$. The change of the output gap is driven by the output gap and the excess of the real interest rate over the natural interest rate $r$, this excess being zero at the steady state. Equ. (3) is also a differential equation with constant coefficients, with $\beta_{1} \leq 0$ $\beta_{2}>0$. Note our model (1) - (3) is written in a way that resembles the New Keynesian model version in continuous time as in Werning (2011). The latter derives the continuous time form from an approximation of the Euler equation of a nonlinear model with preferences, as used in New Keynesian literature on monetary policy models. In Werning (2011) however, the inflation rate responds negatively to the output gap, since he uses a forward looking inflation expectation term driving the actual inflation in a Phillips curve relationship of inflation and output.

Since such a view does not perform well in empirical estimations, see Ball and Mazumder (2014) and Gordon (2011), we use here the Svensson (1997), and Rudebusch and Svensson (1998) version for the Phillips curve. Note that the New Keynesian literature also uses an infinite horizon version of the optimal control problem. We here employ a finite horizon decision model which presumes some limited information agents in the sense of Sims (2006).

From figure 2 we observe that the potential output at 2 and the output gap zero at 2, for all three initial conditions the inflation rate (vertical axis) and output gap (horizontal axis). We can observe small inflation rates in the region of a negative output gap (see region from 1.5 to 2) and a faster rising inflation rate in the region of a positive output gap, where the economy operates beyond full capacity. Thus figure 2 shows already the linear coefficient PC creates, through the feedback effects between output gap, inflation and interest rate, not necessarily a linear PC in the sense of some empirical studies. As figure 2 shows inflation rates can move to zero - our steady state benchmark case - but if there is no or little financial market stress and no credit spread arising, the rise of real interest rates due to disinflation or deflation, might not matter much, as the central bank may bring down the short term nominal rate as well the credit spreads. ${ }^{11}$ This results corresponds also to Borio et al. (2015) who show that debt deflation becomes a problem if the financial market with asset price fall is involved.

\footnotetext{
${ }^{11}$ There maybe a zero bound to the interest rate that the central bank could face, but in our view it is more the danger of the rise of insolvency risk, default premia and jump credit spread that may be the actual danger, see next section.
} 


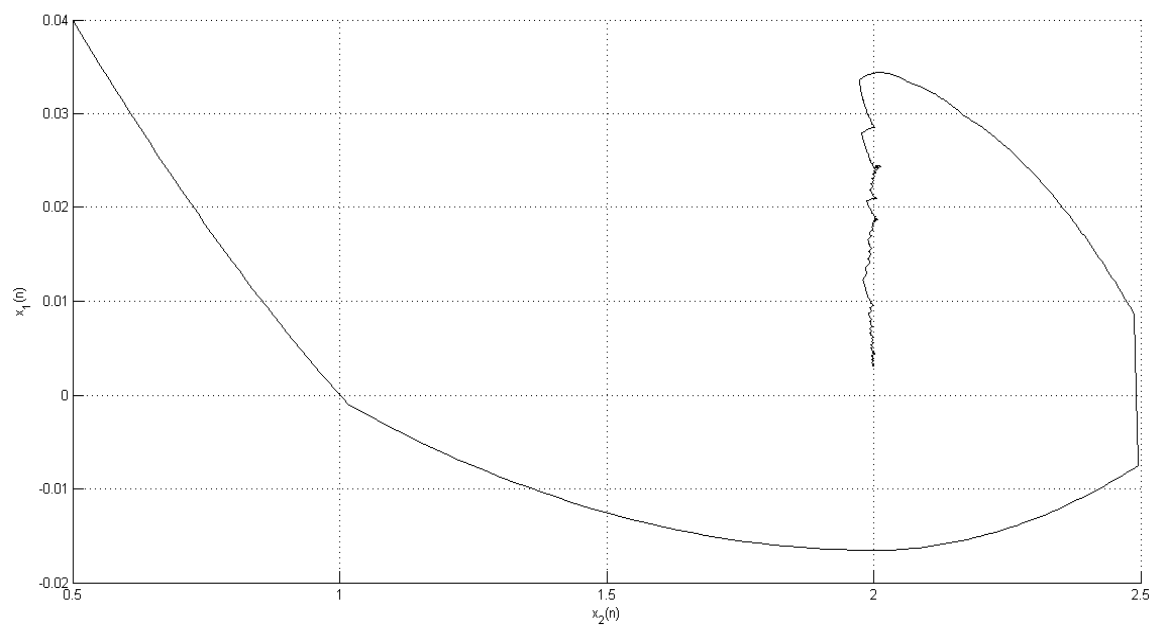

Figure 2: Potential output at 2 and output gap zero at 2, for the initial conditions chosen, the inflation rate (vertical axis) and output gap (horizontal axis): One observes small inflation rates in the region of negative output gap (see region from 1.5 to 2 ) and faster rising inflation rate in the region of positive output gap

\subsection{Model variant with financial stress regime}

In the next variant we discuss the case when there might be a switch from some normal regime with positive output gap and inflation rate to a period with negative output gap, disinflation or deflation and a regime change to financial stress, insolvency risk, rising risk premia and rise of credit spreads. In the normal regime, as depicted in figure 2, there is no financial market stress, and thus no credit spread. Next we want to allow for regime switching as it is demonstrated to be present in other empirical work and discussed in section 2 (see also Schleer and Semmler 2013).

We study a model of regime switching in the IS curve where the actual credit cost, due to rising risk premia, is assumed to move up in a recessionary regime giving rise to financial stress and credit spreads. Inflation rates may also move differently in negative output gap and positive output gap scenarios. ${ }^{12}$ We can employ a regime dependent IS curve as follows:

$$
\begin{gathered}
\dot{y}=\beta_{1} y_{t}-\beta_{2}\left(i_{t}+\delta\left(y_{t}\right)-\pi_{t}-r\right) \\
\delta\left(y_{t}\right)=\mu, \text { for } y<0
\end{gathered}
$$

\footnotetext{
${ }^{12}$ See Gross and Semmler (2015).
} 


$$
\delta\left(y_{t}\right)=0, \text { for } y>0
$$

Thus the regime switching occurs in the linkage of output gap and risk premia, giving rise to credit spreads to be born by firms, households, and/or the sovereign, in a recession. Although the accelerator term, $\beta_{1}$, is the same in equ. (4) as in equ. (3), the output gap itself is impacted by the rising credit spread.

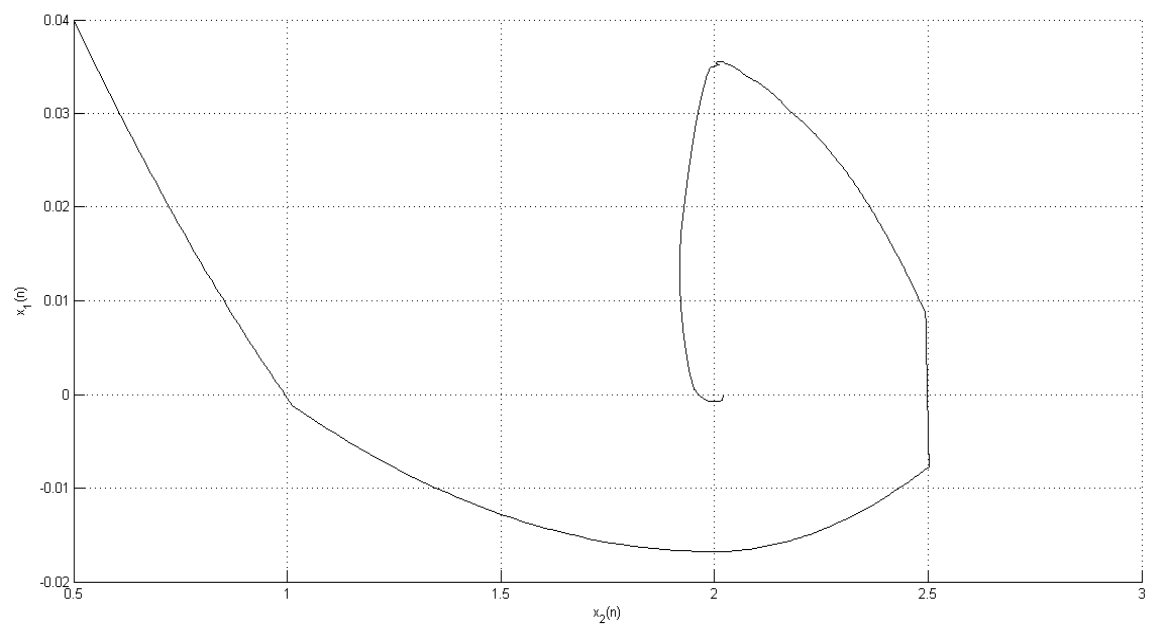

Figure 3: Regime dependent IS equation; potential output at 2, the output gap zero at 2, initial conditions $\pi(0)=0.04$ and output gap $y(0)=0.5$, inflation rate (vertical axis) and output gap (horizontal axis): In the region of a negative output gap, $\delta(y)=\mu=0.12$, for negative output gap regime change to high financial stress causes output to fall, generating disinflation and deflation, then recovery triggers inflation again, until contraction with financial stress re-emerges.

In figure 3 the model with regime switching is solved. As before, potential output is at 2 and the output gap is zero at 2 , for initial condition $\pi(0)=0.04$ and output gap $y(0)=0.5$. The inflation rate (vertical axis) and output gap (horizontal axis) are shown for the region of a negative output gap.

We observe a small response of inflation rates to the output gap in the region of a negative output gap. In the region of a positive output gap, a strong response of inflation to a positive output gap is observable; see the region to the right of the zero output gap, thus there is a weakly changing inflation rate, but there is a strongly changing inflation rate to the right of the zero output gap. Moreover, a huge change of the negative output gap, actual output moving from 0.9 to 2 is needed, to change the inflation rate from 0.01 to -0.011 , whereas the same change occurs already with an overutilization of capacity going from zero to 0.5 .

As to the effects of the regime dependent IS equation, with initial conditions $\pi(0)=0.04$ and output gap $y(0)=0.5$, we observe in the region of a negative output gap, regime switching: 
output remains negative for a long time, with $\delta(y)=0.12$. We have modeled this as a regime change, arising from an insolvency threat, financial market stress, and rise of credit risk and credit spread in the region of a negative output gap. High financial market stress and credit spread cause output to fall, generating disinflation and slight deflation. Thus a process of disinflation or deflation will go hand in glove with a faster decrease of prices but persistent loss of output and employment. Then a recovery maybe slowly emerging with rising inflation rate. So, overall, it is this regime change to financial market stress and credit spreads that is the real peril in a deflationary period, possibly generating a protracted period of a negative output gap. This is what what we want to estimate next in an econometric regime change model with regime dependent effects of shocks.

\section{Multi Regime VAR Results}

\subsection{Methodology}

Linear VAR and orthogonal impulse responses build on strict assumptions concerning the dynamics of the model. It is implicitly assumed that the responses do not change irrespective of the state of the economy. Furthermore, the orthogonalized impulse responses lead to feedback effects which are symmetric with respect to the sign of the shock, linear in terms of their size and independent of the history of the economy (Koop et al. 1996).

However, it has been argued above that the response of an economy changes with respect to financial market conditions. Our model with financial market stress presented in section 3.2 also shows how stress in financial markets influences the behavior of an economy. From an empirical point of view such a model can be evaluated by a multi-regime autoregression (Tong 1978; Tong 1983). In a multivariate setting a multi-regime VAR (MRVAR) can then be defined the following way (cf. Tsay 1998; Mittnik and Semmler 2012):

$$
\mathbf{y}_{\mathbf{t}}=\mathbf{c}_{\mathbf{i}}+\sum_{j=1}^{p} A_{i j} \mathbf{y}_{\mathbf{t}-\mathbf{j}}+\varepsilon_{i t} \quad \text { if } \tau_{i-1}<r_{t-d} \leq \tau_{i}
$$

where $\mathbf{y}_{\mathbf{t}}=\left(y_{1 t}, \ldots, y_{n t}\right)$ and $\mathbf{c}_{\mathbf{i}}$ is a vector of regime-dependent constants. $\tau$ represents the threshold values and $r_{t-d}$ is the threshold variable which may or may not be included in $\mathbf{y}_{\mathbf{t}}$, while $d$ represents the threshold delay with $d \geq 1$. Additionally it is assumed that $\varepsilon_{i t} \sim N I D\left(0, \Sigma_{i}\right)$ and $i=$ $1, \ldots, M$.

As can be seen from equ. (7), a multi-regime VAR defines a piecewise-linear VAR for $M+1$ distinct regimes where the threshold variable $r_{t-d}$ defines the state of the economy. The multiregime VAR outlined in equ. (7) also exhibits interesting characteristics from a theoretical and empirical perspective. From a theoretical point of view it allows us to model state-dependent behavior of economic relations, while its relatively simple structure allows for estimation by least-squares conditional on the threshold variable $r_{t-d}$.

Like in the case of a linear VAR model, we are interested in the effects of shocks to certain endogenous variables on other endogenous variables. However, as discussed above, orthogonal impulse responses are inappropriate for non-linear models. Therefore generalized impulse response functions (GIRF) (Koop et al. 1996) will be used here, which are capable of capturing 
asymmetries and history dependence of shocks to the system. The GIRF are defined as follows:

$$
\operatorname{GIRF}_{y}\left(n, V_{t}, \Omega_{t-1}\right)=\mathrm{E}\left[\mathbf{y}_{\mathbf{t}+\mathbf{n}} \mid V_{t}, \Omega_{t-1}\right]-\mathrm{E}\left[\mathbf{y}_{\mathbf{t}+\mathbf{n}} \mid \Omega_{t-1}\right]
$$

where $\Omega_{t-1}$ is the history/state of the economy at a specific point in time. In our case, where we are estimating a MRVAR with $p$ lags, $\Omega_{t-1}$ consists of $\mathbf{y}_{\mathbf{t}-\mathbf{1}}, \ldots, \mathbf{y}_{\mathbf{t}-\mathbf{p}}$, while $V_{t}$ depicts a shock to a specific variable of our system and $n$ represents the forecast horizon. The procedure can be briefly summarized as follows: ${ }^{13}$ we split our data set into subsets of observations according to the regimes they belong to. Then we take a regime $i$ and a random starting value from $i$ and simulate the model with bootstrapped (regime-specific) residuals. We repeat the simulation with the same starting value and bootstrapped residuals, but we add an additional shock to one variable in the starting period. This procedure is repeated $R$-times for a given starting value and randomly drawn residuals and afterwards the average of the simulations is computed. By the law of large numbers as $R \rightarrow \infty$, the simulations converge to the conditional expectations given in (8).

We repeat this procedure $l$-times for regime $i$, where the starting values are drawn randomly from the subset of observations of regime $i$ with replacement. The simulation is then undertaken for each regime on its own which gives the regime-dependent GIRF.

\subsection{Empirical Analysis}

In our analysis we build on a four dimensional MRVAR where $\mathbf{y}_{\mathbf{t}}$ consists of change in GDP, inflation rates, the spread between long-term and short-term interest rates and the FCI, where the FCI also acts as the threshold variable. Thus we estimate a MRVAR with an endogenous threshold variable. As mentioned before, we use here the spread between the long and the short interest rate because of the high covariation of the term spread and the private credit cost. ${ }^{14}$

As already discussed in the last section, a threshold model enables us to take nonlinearities with respect to financial market conditions into account. As an alternative, one could also model the nonlinearities using a Markov switching model (MSVAR) as in Hamilton (1989). However, in MSVAR models states of the economy are not observable and therefore don't have an obvious interpretation, while we are assuming that the (observable) FCI is capable of distinguishing between low stress and high stress regimes in financial markets. The a priori definition of regimes, and the possibility of classifying observations according to the regimes they belong to, makes the MRVAR also more fruitful for policy analysis (see also Mittnik and Semmler 2012).

However, before estimating the model, we have to test for threshold effects first. We use the test developed by Lo and Zivot (2001) to test the null hypothesis of linearity against the alternative of threshold effects. The test was conducted with 1000 bootstrap replications for each country and a trimming value of 0.2 which guarantees that each regime contains at least $20 \%$ of all observations. The results are shown in tables (1) through (4). As can be seen, we are testing a linear model against two different alternatives, namely a model with one threshold and a model with two thresholds. However, as our number of observations are rather limited with a total of 129 observations, we decided to estimate a model with only one threshold for

\footnotetext{
${ }^{13} \mathrm{~A}$ detailed algorithm for computing the generalized impulse responses is described in appendix A.

${ }^{14}$ See again Corsetti et al. (2012) and Blanchard and Leigh (2013).
} 
all countries. The use of one threshold is appropriate for Germany, Spain and Italy, but not for France, as can be seen from the tables. Although the tests would suggest a linear model for France, we decided to estimate a MRVAR for reasons of comparison for France as well.

As in the case of the linearity test, we use a trimming value of 0.2 for the MRVAR estimation as well. The threshold value, as well as the threshold delay, are obtained by a grid search, where the sum of squared residuals (SSR) is minimized. The lag length choice is informed by the Schwarz criterion, where the lag length is constant across regimes for each country. The Schwarz criterion suggests a lag length of one for each country and the SSR are minimized with a threshold delay value of one as well. The estimation results are shown in tables (9) through (12), where change in GDP is ordered first $\left(y_{t}^{1}\right)$, the inflation rate is ordered second $\left(y_{t}^{2}\right)$, followed by the interest rate spread $\left(y_{t}^{3}\right)$ and the FCI $\left(y_{t}^{4}\right)$. Moreover, the threshold values of our estimates are indicated in the tables by $T h$.

\begin{tabular}{lrrrrrr}
\hline & $90 \%$ & $95 \%$ & $97.5 \%$ & $99 \%$ & Test Statistic & P-Value \\
\hline Crit. Value MRVAR(1) & 38.91684 & 42.79938 & 47.95230 & 54.10266 & 42.66837 & 0.05200 \\
Crit. Value MRVAR(2) & 70.42317 & 76.34283 & 80.29903 & 89.37402 & 59.62706 & 0.32800 \\
\hline
\end{tabular}

Table 1: Germany: Test of linear VAR against MRVAR(1) and MRVAR(2)

\begin{tabular}{lrrrrrr}
\hline & $90 \%$ & $95 \%$ & $97.5 \%$ & $99 \%$ & Test Statistic & P-Value \\
\hline Crit. Value MRVAR(1) & 41.07914 & 45.40710 & 47.66195 & 52.55821 & 25.4118 & 0.6650 \\
Crit. Value MRVAR(2) & 72.96317 & 78.31620 & 81.58928 & 87.77751 & 54.32389 & 0.57700 \\
\hline
\end{tabular}

Table 2: France: Test of linear VAR against MRVAR(1) and MRVAR(2)

\begin{tabular}{lrrrrrr}
\hline & $90 \%$ & $95 \%$ & $97.5 \%$ & $99 \%$ & Test Statistic & P-Value \\
\hline Crit. Value MRVAR(1) & 40.96873 & 45.07202 & 48.99541 & 51.11692 & 49.2769 & 0.0200 \\
Crit. Value MRVAR(2) & 75.78246 & 81.95585 & 85.05443 & 90.21488 & 86.4230 & 0.0200 \\
\hline
\end{tabular}

Table 3: Spain: Test of linear VAR against MRVAR(1) and MRVAR(2)

\begin{tabular}{lrrrrrr}
\hline & $90 \%$ & $95 \%$ & $97.5 \%$ & $99 \%$ & Test Statistic & P-Value \\
\hline Crit. Value MRVAR(1) & 42.83848 & 45.74163 & 51.35114 & 54.48933 & 56.25111 & 0.00600 \\
Crit. Value MRVAR(2) & 76.56803 & 82.64711 & 87.84411 & 96.85304 & 90.32876 & 0.02000 \\
\hline
\end{tabular}

Table 4: Italy: Test of linear VAR against MRVAR(1) and MRVAR(2) 
$\left(\begin{array}{l}y_{t}^{1} \\ y_{t}^{2} \\ y_{t}^{3} \\ y_{t}^{4}\end{array}\right)=\left\{\begin{array}{c}\left(\begin{array}{c}0.0025 \\ 0.0030 \\ 0.0005 \\ 0.2385\end{array}\right)+\left(\begin{array}{cccc}-0.0617 & 0.1571 & 0.8876 & 0.0007 \\ 0.1079 & 0.4640 & -0.3612 & -0.0002 \\ -0.0128 & -0.0160 & 0.8632 & -2.7 \mathrm{e}-05 \\ -2.0734 & -16.7613 & 13.5007 & 1.0469\end{array}\right)\left(\begin{array}{l}y_{t-1}^{1} \\ y_{t-1}^{2} \\ y_{t-1}^{3} \\ y_{t-1}^{4}\end{array}\right) \\ \left(\begin{array}{c}-0.0069 \\ 0.0069 \\ 0.0008 \\ -0.2172\end{array}\right)+\left(\begin{array}{cccc}0.0551 & 1.1776 & 2.5727 & -0.0017 \\ 0.0470 & 0.3310 & -0.8237 & -0.0005 \\ -0.0181 & -0.1385 & 0.9118 & 0.0001 \\ 12.8580 & 46.1625 & -158.1838 & 0.9248\end{array}\right)\left(\begin{array}{c}y_{t-1}^{1} \\ y_{t-1}^{2} \\ y_{t-1}^{3} \\ y_{t-1}^{4}\end{array}\right) \quad \text { if } \mathrm{Th}>0.8654\end{array}\right.$

Table 5: MRVAR(1) for Germany

$$
\left(\begin{array}{l}
y_{t}^{1} \\
y_{t}^{2} \\
y_{t}^{3} \\
y_{t}^{4}
\end{array}\right)=\left\{\begin{array}{c}
\left(\begin{array}{c}
0.0034 \\
0.0038 \\
0.0006 \\
-0.1234
\end{array}\right)+\left(\begin{array}{cccc}
0.1630 & -0.0379 & 0.4128 & 2.4 \mathrm{e}-07 \\
-0.1302 & 0.7306 & -0.1869 & 0.0009 \\
0.0163 & -0.0041 & 0.8200 & 0.0002 \\
-13.5918 & -16.9884 & 34.8983 & 0.7596
\end{array}\right)\left(\begin{array}{c}
y_{t-1}^{1} \\
y_{t-1}^{2} \\
y_{t-1}^{3} \\
y_{t-1}^{4}
\end{array}\right) \\
\left(\begin{array}{c}
-0.0020 \\
-0.0011 \\
0.0011 \\
1.4409
\end{array}\right)+\left(\begin{array}{cccc}
0.4200 & 0.2393 & 0.7852 & -0.0008 \\
0.0088 & 0.9886 & 0.4100 & -0.0003 \\
-0.0147 & -0.0382 & 0.7338 & 0.0002 \\
-20.8828 & -28.1160 & -161.0134 & 0.7839
\end{array}\right)\left(\begin{array}{c}
y_{t-1}^{1} \\
y_{t-1}^{2} \\
y_{t-1}^{3} \\
y_{t-1}^{4}
\end{array}\right) \quad \text { if Th }>0.6360
\end{array}\right.
$$

Table 6: MRVAR(1) for France

$$
\left(\begin{array}{l}
y_{t}^{1} \\
y_{t}^{2} \\
y_{t}^{3} \\
y_{t}^{4}
\end{array}\right)=\left\{\begin{array}{l}
\left(\begin{array}{l}
0.0018 \\
0.0022 \\
0.0016 \\
0.4454
\end{array}\right)+\left(\begin{array}{cccc}
0.6112 & -0.0450 & 0.2651 & -0.0005 \\
0.3279 & 0.3097 & -0.2591 & -0.0010 \\
-0.0473 & -0.0422 & 0.7500 & 0.0002 \\
-39.9579 & 8.5823 & -76.8477 & 1.0030
\end{array}\right)\left(\begin{array}{l}
y_{t-1}^{1} \\
y_{t-1}^{2} \\
y_{t-1}^{3} \\
y_{t-1}^{4}
\end{array}\right) \\
\left(\begin{array}{l}
0.0006 \\
0.0026 \\
0.0009 \\
0.2009
\end{array}\right)+\left(\begin{array}{cccc}
0.8777 & 0.0134 & -0.0680 & 0.0001 \\
-0.0347 & 0.8042 & -0.1756 & 0.0002 \\
-0.0544 & -0.0769 & 0.5760 & 0.0011 \\
-41.5978 & -2.3862 & -26.0725 & 1.0491
\end{array}\right)\left(\begin{array}{c}
y_{t-1}^{1} \\
y_{t-1}^{2} \\
y_{t-1}^{3} \\
y_{t-1}^{4}
\end{array}\right)
\end{array}\right.
$$

Table 7: MRVAR(1) for Spain

$$
\left(\begin{array}{l}
y_{t}^{1} \\
y_{t}^{2} \\
y_{t}^{3} \\
y_{t}^{4}
\end{array}\right)=\left\{\begin{array}{l}
\left(\begin{array}{c}
0.0010 \\
0.0012 \\
0.0004 \\
-0.0916
\end{array}\right)+\left(\begin{array}{cccc}
0.1643 & 0.0369 & -0.2186 & -0.0011 \\
0.0103 & 0.7872 & -0.0273 & -0.0006 \\
-0.0104 & -0.0056 & 0.8484 & 0.0002 \\
-28.9487 & 10.0175 & -2.3704 & 0.8848
\end{array}\right)\left(\begin{array}{l}
y_{t-1}^{1} \\
y_{t-1}^{2} \\
y_{t-1}^{3} \\
y_{t-1}^{4}
\end{array}\right) \quad \text { if Th }<-0.0725 \\
\left(\begin{array}{c}
-0.0062 \\
0.0015 \\
0.0035 \\
1.2107
\end{array}\right)+\left(\begin{array}{cccc}
0.2550 & 0.1468 & 2.3656 & -0.0030 \\
0.0141 & 0.9418 & -0.1367 & 1.8 \mathrm{e}-05 \\
-0.0291 & -0.0963 & 0.4025 & 0.0003 \\
5.9333 & -43.7088 & -176.0144 & 1.0726
\end{array}\right)\left(\begin{array}{l}
y_{t-1}^{1} \\
y_{t-1}^{2} \\
y_{t-1}^{3} \\
y_{t-1}^{4}
\end{array}\right) \quad \text { if Th }>-0.0725
\end{array}\right.
$$

Table 8: MRVAR(1) for Italy 
As we are interested in the effects of deflationary shocks on the term structure, we simulate the GIRF with a negative shock to inflation of one standard deviation in the next step. Figures(4) (7) display the effects of a deflationary shock for Germany, France, Spain and Italy, where $90 \%$ confidence bands are also shown. The response of the spread during tranquil periods is depicted on the left for all four countries, while the right graphs show the responses during a time of financial stress.
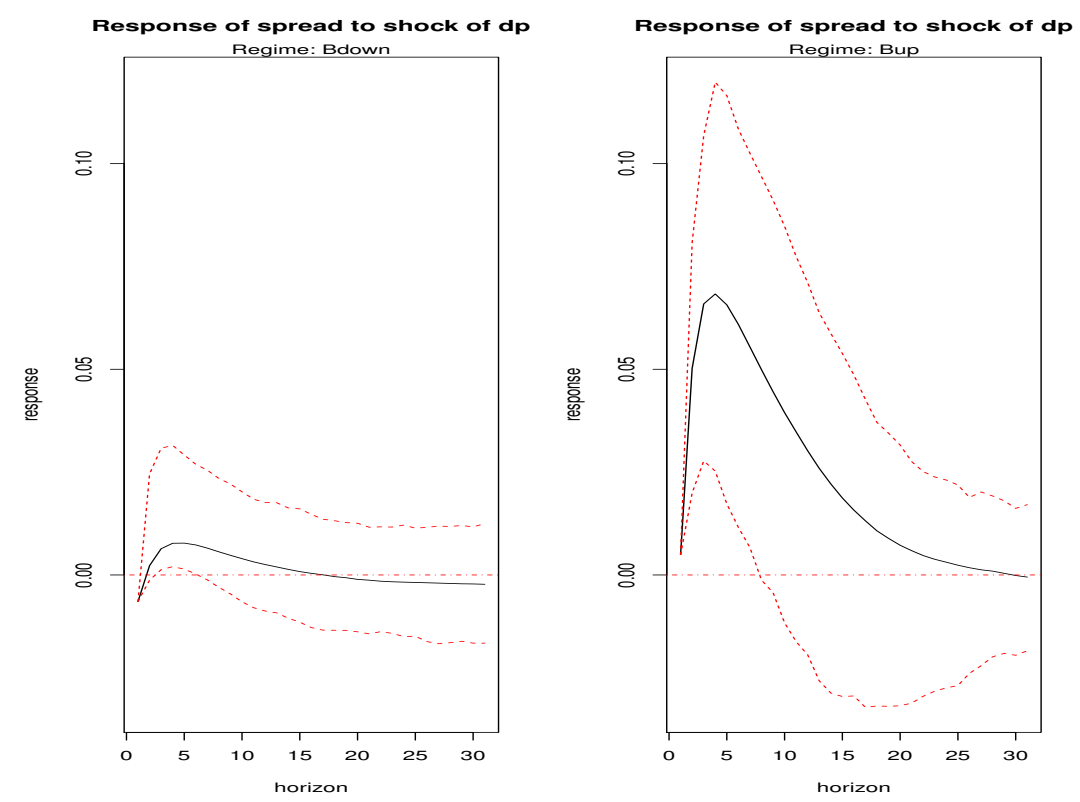

Figure 4: Germany: Response of interest rate spread to deflationary shock of 1 s.d.; low stress regime left, high stress regime right

As already discussed in the introduction, Bordo and Filardo (2005) and Borio et al. (2015) find evidence that the effects of deflations depend on the state of the financial market. If asset prices fall and default risk rises, financial risk has a magnifying effect in case of a deflationary process. When taking a look at the impulse responses, we see that during a "tranquil" period the spread increases initially in Germany, but remains rather small. In the long run the effect fades out and becomes slightly negative. Also for France, the spread increases initially. The effect is stronger than in Germany. But eventually the spread decreases. The initial effects are stronger in Italy and Spain, than in Germany and France. Furthermore, while the spread moves towards zero for Italy, it becomes negative in Spain.

The effects change dramatically in a situation of financial risk and financial stress. While the spread in Germany and France rises initially, it starts declining in Germany after 4 quarters and in France after 8 quarters. For Spain and Italy the results are very different during a period of economic stress as can be seen from figures 6 and 7. While the spread reaches its maximum for Spain after 4 quarters as well and starts declining afterwards, it stabilizes at a higher level compared to Germany and France, while Italy is experiencing the largest spread of all countries with a very slow recovery. In the end, default and financial risk and stress seem to be connected 

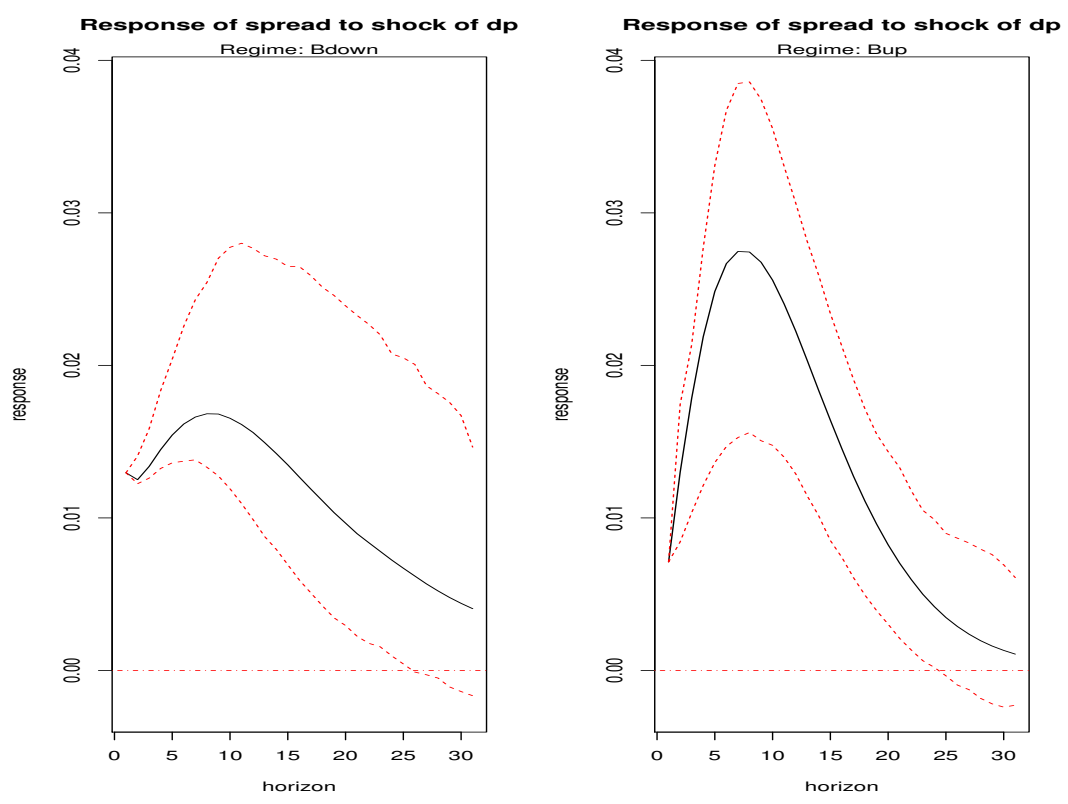

Figure 5: France: Response of interest rate spread to deflationary shock of 1 s.d.; low stress regime left, high stress regime right
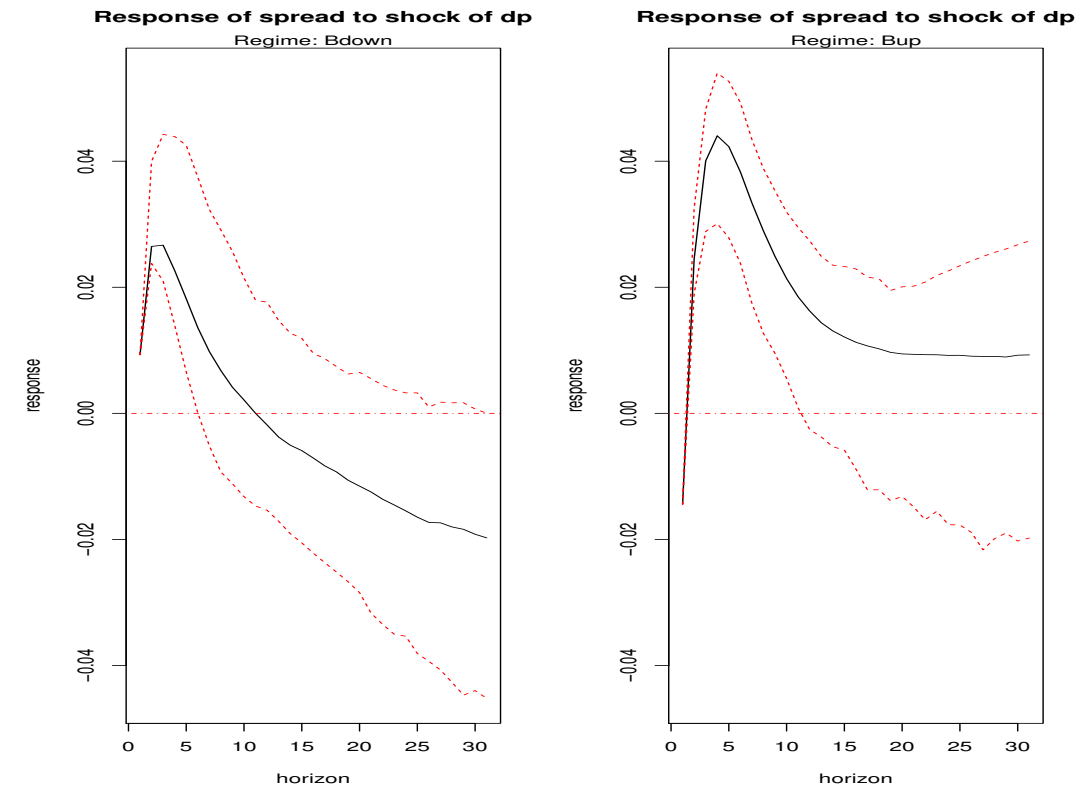

Figure 6: Spain: Response of interest rate spread to deflationary shock of 1 s.d.; low stress regime left, high stress regime right 

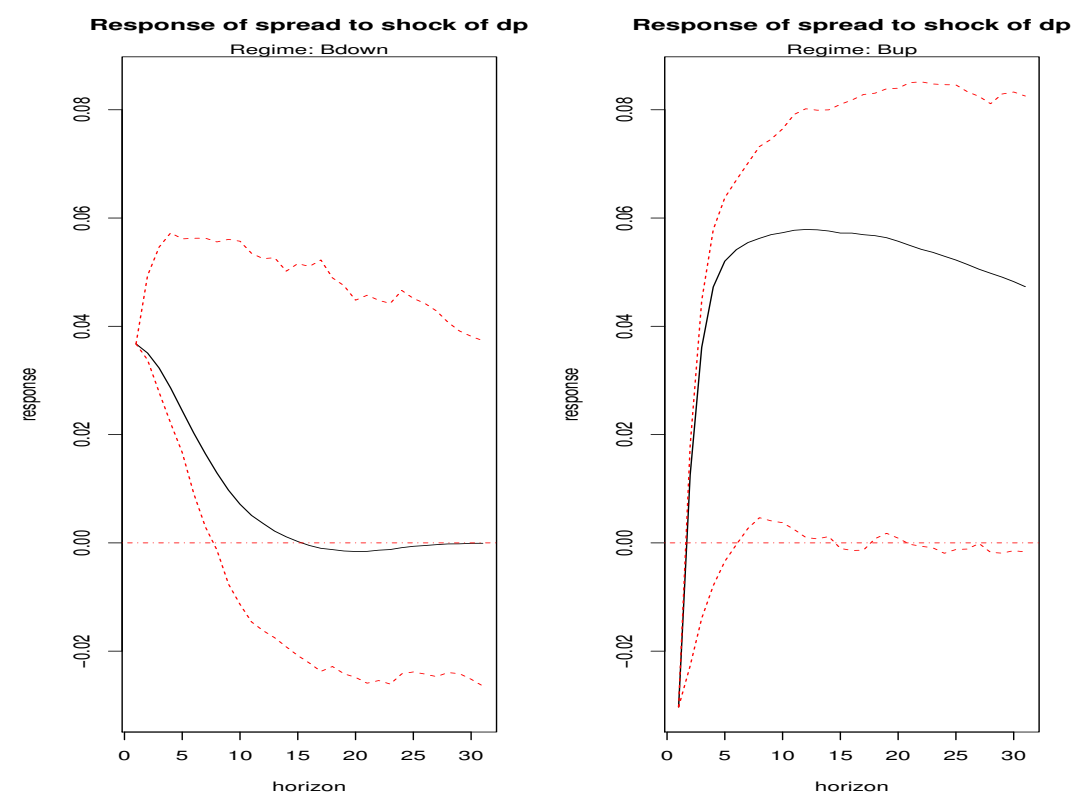

Figure 7: Italy: Response of interest rate spread to deflationary shock of 1 s.d.; low stress regime left, high stress regime right

with a much stronger rise in the risk premia in the peripheral countries of the Euro area compared with the two core countries.

\section{Conclusion}

As demonstrated in the paper there is a wide spread concern in the Euro area that there might be perils of a deflationary process in Europe. The Euro area is currently under threat of a debt deflation and secular stagnation. Though empirical evidence seems to suggest that secular stagnation and debt deflation in the Euro area maybe be rather slow, yet what appears as major peril is that the debt deflation with a lack of economic growth, rising real interest rates and further rising debt may trigger household defaults, defaults of firms and banks, default risk of certain sectors of the economy or sovereign default threats. It is this rising default and financial crisis risk that may lead to a regime of a slowly moving debt crisis with perils for the banking sector, high financial market stress and a rapid rise of risk premia and credit spreads. In order to explore those issues a macro policy model of Svensson type is introduced, exhibiting a regime of low and high financial stress. We then employed a four dimensional multi-regime VAR on Euro area time series data on output, inflation rate, financial market stress and credit spread between long and short interest rates. The empirical results on the multi regime VAR for the Euro area time series data support the theoretical model and the claim that in particular Southern Euro area countries are affected by debt deflation combined with default and financial market risk. 


\section{A. GIRF algorithm}

We follow the approach of Caggiano et al. (2015) in computing the GRIF. The algorithm works the following way:

1. Consider the set of all observations which contains $T=129$ observations and runs from 1980Q4 until 2013Q1. This allows us to build $T-p+1$ histories. With a lag length of $p=1$ this implies that we have 129 histories to draw from (with replacement). The histories are split into $M$ regime-subsets $\left(\Omega_{1}, \ldots, \Omega_{M}\right)$ according to the regime they belong to.

2. Take a set of histories $\left(\Omega_{i}\right)$ out of one of the $M$ subsets from step (1) and compute the regime-dependent Variance-Covariance Matrix $\Sigma_{i}$.

3. Cholesky decompose $\Sigma_{i}$ which gives $\Sigma_{i}=C_{i} C_{i}^{\prime}$ and orthogonalize the regime-dependent residuals to get the structural shocks: $e_{i}=C_{i}^{-1} \varepsilon_{i}$

4. Draw a history $\omega_{j} \in \Omega_{i}$.

5. From $e_{i}$ draw a set of $n$ four-dimensional structural errors $e_{i}^{*}=\left(e_{i t}, \ldots, e_{i t+n}\right)$ with replacement, where the contemporaneous correlation of the structural errors is taken into account. Afterwards transform the residuals back into their reduced form representation: $\varepsilon_{i}^{*}=C_{i} e_{i}^{*}$.

6. Use the history from step (4) and the structural errors from step (5) to simulate the model with the parameters from the MRVAR model.

7. Take the structural errors from step (5) and add an additional shock in period $t: e_{i}^{v}=$ $\left(e_{i t}+v_{t}, \ldots, e_{i t+n}\right)$. Then compute the reduced form errors as in (5).

8. Use the history from step (4) and the structural errors from step (7) to simulate the model.

9. Repeat steps (5) through (8) $R=100$ times and take the average of the simulations from step (6) and from step (8). The difference of the averages represents the GIRF for history $j$.

10. Repeat steps (2) through (9) $l=500$ times for regime $i$ where the histories are drawn from $\Omega_{i}$ with replacement. Take the average over all estimated $\operatorname{GIRF}^{i}\left(G I R F^{i, 1}, \ldots, G I R F^{i, l}\right)$ which represents the GIRF for regime $i$.

11. Repeat steps (2) through (10) for all regimes to get the GIRF for all $M$ regimes.

12. The confidence intervals are computed by taking the $5 \%$ and $95 \%$ percentile of the densities of the simulated GIRF $\left(G I R F^{1}, \ldots, G I R F^{l}\right)$ for each regime. 


\section{B. Data}

Our dataset was constructed from two data sources. The first three variables (change in GDP, inflation rate and the interest rate spread) were taken from the GVAR project (Smith and Galesi 2014). Therefore our data is based on the International Financial Statistics (IFS) database where change in GDP is the first difference of real GDP (Concept: Gross Domestic Product, Real Index, Quarterly, $2005=100$ ) and the inflation rate corresponds to Consumer Prices, All items, Quarterly, $2005=100$. The interest rate spread is calculated as the difference between longterm and short-term interest rate, where the long-term interest rate corresponds to Interest Rates, Government Securities, Government Bonds concept, while the short term interest rate is taken from Interest Rates, Treasury Bill Rate.

Our fourth variable, the ZEW Financial Condition Indices (FCI), which acts as the endogenous threshold variable in our MRVAR model, is taken from Schleer and Semmler (2013). The index represents financial sector conditions and stress with a focus on the banking sector. The index covers the banking sector, securities markets and foreign exchange markets.

A more detailed description of the data can be found in Smith and Galesi (2014) and in Schleer and Semmler (2013). 


\section{References}

Andrew Ang and Monika Piazzesi. A no-arbitrage vector autoregression of term structure dynamics with macroeconomic and latent variables. Journal of Monetary Economics, 50(4): 745-787, 2003.

Laurence Ball and Sandeep Mazumder. A phillips curve with anchored expectations and shortterm unemployment. Working Paper 20715, National Bureau of Economic Research, November 2014.

Ben Bernanke and Mark Gertler. Agency Costs, Net Worth, and Business Fluctuations. American Economic Review, 79(1):14-31, March 1989.

Ben S. Bernanke. Nonmonetary effects of the financial crisis in the propagation of the great depression. The American Economic Review, 73(3):pp. 257-276, 1983.

Ben S. Bernanke. The macroeconomics of the great depression: A comparative approach. Journal of Money, Credit and Banking, pages 1-28, 1995.

Ben S. Bernanke, Mark Gertler, and Simon Gilchrist. The financial accelerator in a quantitative business cycle framework. In J. B. Taylor and M. Woodford, editors, Handbook of Macroeconomics, volume 1 of Handbook of Macroeconomics, chapter 21, pages 1341-1393. Elsevier, 1999.

Olivier J. Blanchard and Daniel Leigh. Growth Forecast Errors and Fiscal Multipliers. IMF Working Papers 13/1, International Monetary Fund, January 2013.

Michael Bordo and Andrew Filardo. Deflation in a historical perspective. BIS Working Papers 186, Bank for International Settlements, November 2005.

Claudio E. V. Borio, Magdalena Erdem, Andrew J. Filardo, and Boris Hofmann. The costs of deflations: A historical perspective. BIS Quarterly Review, March 2015, 2015.

Giovanni Caggiano, Efrem Castelnuovo, Valentina Colombo, and Gabriela Nodari. Estimating fiscal multipliers: News from a non-linear world. The Economic Journal, 125(584):746-776, 2015.

Lawrence J. Christiano, Roberto Motto, and Massimo Rostagno. The Great Depression and the Friedman-Schwartz Hypothesis. NBER Working Papers 10255, National Bureau of Economic Research, Inc, January 2004.

Lorenzo Codogno, Carlo Favero, and Alessandro Missale. Yield spreads on emu government bonds. Economic Policy, 18(37):503-532, 2003.

Giancarlo Corsetti, Keith Kuester, André Meier, and Gernot Müller. Sovereign Risk, Fiscal Policy, and Macroeconomic Stability. CEPR Discussion Papers 8779, C.E.P.R. Discussion Papers, January 2012. 
ECB. Monthly bulletin 06 2014. Technical report, European Central Bank, 2014.

Charles L. Evans and David A. Marshall. Economic determinants of the nominal treasury yield curve. Journal of Monetary Economics, 54(7):1986-2003, October 2007.

Roger E.A. Farmer, Daniel F. Waggoner, and Tao Zha. Understanding markov-switching rational expectations models. Journal of Economic Theory, 144(5):1849 - 1867, 2009.

Irving Fisher. The debt-deflation theory of great depressions. Econometrica, 1(4):337-357, 1933.

Robert J. Gordon. Does the 'new economy' measure up to the great inventions of the past? Working Paper 7833, National Bureau of Economic Research, August 2000.

Robert J. Gordon. The history of the phillips curve: Consensus and bifurcation. Economica, 78 (309):10-50, 2011.

Marco Gross and Willi Semmler. Convex phillips curves: Literature review, a theoretical model and an empirical, analysis for the euro area. Technical report, ECB working paper, 2015.

Lars Grüne, Willi Semmler, and Marleen Stieler. Using Nonlinear Model Predictive Control for Dynamic Decision Problems in Economics. EcoMod2013 5782, EcoMod, June 2013.

Refet S. Gürkaynak and Jonathan H. Wright. Macroeconomics and the term structure. Journal of Economic Literature, 50(2):331-67, 2012.

James D Hamilton. A New Approach to the Economic Analysis of Nonstationary Time Series and the Business Cycle. Econometrica, 57(2):357-84, March 1989.

C.P. Kindleberger and R.Z. Aliber. Manias, Panics and Crashes: A History of Financial Crises, Sixth Edition. Palgrave Macmillan, 2011. ISBN 9780230365353.

Nobuhiro Kiyotaki and John Moore. Credit Cycles. Journal of Political Economy, 105(2): 211-48, April 1997.

Richard C Koo. Balance sheet recession is the reason for secular stagnation. In Coen Teulings and Richard Baldwin, editors, Secular Stagnation: Facts, Causes and Cures. CEPR, 2014.

Gary Koop, M.Hashem Pesaran, and Simon M. Potter. Impulse response analysis in nonlinear multivariate models. Journal of Econometrics, 74(1):119 - 147, 1996.

Ming Chien Lo and Eric Zivot. Threshold cointegration and nonlinear adjustment to the law of one price. Macroeconomic Dynamics, 5:533-576, 92001.

Bennett T. McCallum. Monetary policy and the term structure of interest rates. Working Paper 4938, National Bureau of Economic Research, November 1994.

H.P. Minsky. Debt deflation processes in today's institutional environment. PSL Quarterly Review, 35(143), 2013. 
Stefan Mittnik and Willi Semmler. Regime dependence of the fiscal multiplier. Journal of Economic Behavior \& Organization, 83(3):502-522, 2012.

Stefan Mittnik and Willi Semmler. The real consequences of financial stress. Journal of Economic Dynamics and Control, 37(8):1479-1499, 2013.

Glenn D. Rudebusch and Lars E. O. Svensson. Policy rules for inflation targeting. Working Paper 6512, National Bureau of Economic Research, April 1998.

Yuliy Sannikov and Markus K. Brunnermeier. A Macroeconomic Model with a Financial Sector. 2010 Meeting Papers 1114, Society for Economic Dynamics, 62010.

Frauke Schleer and Willi Semmler. Financial sector and output dynamics in the euro area: Nonlinearities reconsidered. ZEW Discussion Papers 13-068, ZEW - Zentrum für Europäische Wirtschaftsforschung / Center for European Economic Research, 2013.

Frauke Schleer, Willi Semmler, and Julian Illner. Overleveraging in the banking sector: Evidence from europe. ZEW Discussion Papers 14-066, ZEW - Zentrum für Europäische Wirtschaftsforschung / Center for European Economic Research, 2014.

Willi Semmler and Pu Chen. Financial stress, regime switching and macrodynamics: Theory and empirics for the us, the eu and non-eu countries. Economics: The Open-Access, OpenAssessment E-Journal, 8(2014-20), 2014.

Willi Semmler and Christian R. Proaño. Escape routes from sovereign default risk in the euro area. ZEW Discussion Papers 15-020, ZEW - Zentrum für Europäische Wirtschaftsforschung / Center for European Economic Research, 2015.

Christopher A. Sims. Rational inattention: Beyond the linear-quadratic case. The American Economic Review, 96(2):pp. 158-163, 2006.

L.V. Smith and A. Galesi. Gvar toolbox 2.0, https://sites.google.com/site/gvarmodelling/gvartoolbox, 2014.

Lawrence H Summers. U.S. Economic Prospects: Secular Stagnation, Hysteresis, and the Zero Lower Bound. Business Economics, 49(2):65-73, April 2014.

Lars E. O. Svensson. Inflation forecast targeting: Implementing and monitoring inflation targets. European Economic Review, 41(6):1111-1146, June 1997.

Coen Teulings and Richard Baldwin. Introduction. In Coen Teulings and Richard Baldwin, editors, Secular Stagnation: Facts, Causes and Cures. CEPR, 2014.

James Tobin. Keynesian Models of Recession and Depression. Cowles Foundation Discussion Papers 387, Cowles Foundation for Research in Economics, Yale University, 61975.

H. Tong. Threshold models in non-linear time series analysis. Lecture notes in statistics. Springer-Verlag, 1983. ISBN 9780387909189. 
Howell Tong. Pattern Recognition and Signal Processing. NATO ASI Series E: Applied Sc.(29), chapter On a trehold model, pages 575-586. Sijthoff \& Noordhoff, Netherlands, 1978.

Ruey S. Tsay. Testing and modeling multivariate threshold models. Journal of the American Statistical Association, 93:1188-1202, 1998.

Goetz von Peter. Debt-deflation: concepts and a stylised model. BIS Working Papers 176, Bank for International Settlements, April 2005.

Ivan Werning. Managing a liquidity trap: Monetary and fiscal policy. Working Paper 17344, National Bureau of Economic Research, August 2011.

John C. Williams and John B. Taylor. A Black Swan in the Money Market. American Economic Journal: Macroeconomics, 1(1):58-83, January 2009. 